\title{
CATARACT EXTRACTION IN A CASE OF CONGENITAL COLOBOMA OF THE IRIS* ${ }^{\dagger}$
}

\author{
BY
}

\author{
DAVID H. NIXSEAMAN \\ Ballochmyle Hospital, Mauchline, Ayrshire
}

THIS case of cataract in a woman with bilateral congenital colobomata of the iris, and its extraction, is presented because of its rarity as a surgical event.

The incidence of coloboma of the iris and retina is variously given by different workers. Clarke and his colleagues found twelve cases of typical colobomata of the iris in a series of 500 ocular abnormalities (Clarke, Bancroft, Allen, Wang, and Eaton, 1954), and it is generally agreed that the condition occurs bilaterally in more than 60 per cent. of cases. Coloboma of the iris (in degrees varying from a notch in the pupil margin, to involvement of the retina and optic disc) is often associated with congenital cataract or other congenital abnormalities, according to Duke-Elder (1964), and in a series of German families (Behnke, 1965) three members in one family had partial aniridia with congenital or early cataract. The patient here described also presented with cataracts suggestive of congenital origin, as well as coloboma of the iris and retina.

\section{Case Report}

A woman aged 59 years was aware of having poor sight since birth, especially in the right eye, and had worn glasses for myopia (of the order of $-6 \mathrm{D} \mathrm{sph}$. for each eye) from an early age. During the past 10 years her vision had progressively deteriorated, and she had become unable to read or to get about much. There was no family history of ocular defects.

When she was referred to one of my colleagues, he found that the visual acuity in the right eye, which was divergent, was only "hand movements", but in the left it was "counting fingers" at three metres. As Fig. 1 shows, she had bilateral typical congenital colobomata of the iris, immature cataracts, and the appearances suggestive of retinal colobomata, especially in the right eye. It was therefore thought that the left eye would benefit more from lens extraction than the right.

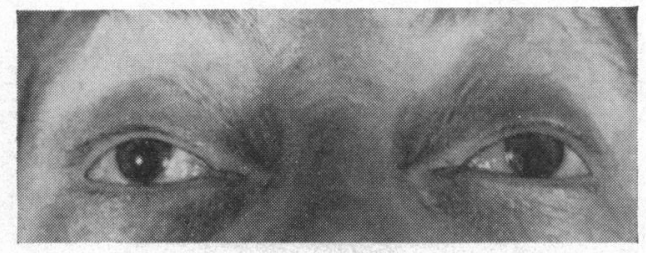

Fig. 1.-Bilateral symmetrical coloboma of iris.

The cataracts were not of the usual senile variety, but took the form of irregular globular opacities, mainly in the anterior subcapsular region, especially in the lower quadrants underlying the coloboma, in each eye. There were, however, senile cataractous changes superimposed, which accounted for the recent deterioration in vision, but there was no sign of notching of the lens of the type often accompanying coloboma of the iris.

* Received for publication May $30, \cdot 1967$.

$\dagger$ Address for reprints: as above. 
Pre-operative Procedure.-The operation was begun under local anaesthesia, but as the patient developed convulsions, and became momentarily unconscious, possibly because of Xylocaine sensitivity, it was later performed under general anaesthesia, which might well have been more suitable in the first place. She was given Diamox $250 \mathrm{mg}$. intravenously, and a further $250 \mathrm{mg}$. orally, one hour before operation to ensure a low intra-ocular pressure. An intravenous injection of ethamsylate ("Dicynene") 2 ampoules was also given one hour before as a haemostatic.

Operation.-A general anaesthetic was begun with relaxants, together with oxygen and ether.

The left eye was prepared in the customary fashion for cataract extraction, using lid stitches and a pre-placed corneo-scleral suture, but in the 6 o'clock meridian. The anterior chamber was opened with a von Graefe knife held in the right hand (standing by the patient's left side) and cutting downwards, the eye being fixed by Barraquer's forceps at the limbus, at the 12 o'clock meridian (Fig. 2).

The corneal suture was then loosely tied, and the lens was grasped by intracapsular forceps at the inferior pole. To avoid the danger of losing vitreous through the wide coloboma, no attempt was made to rupture the zonule by exterior counter-pressure. The lens was simply and easily extracted between intracapsular forceps and a vectis, using the sliding technique (Figs 3 to 5).

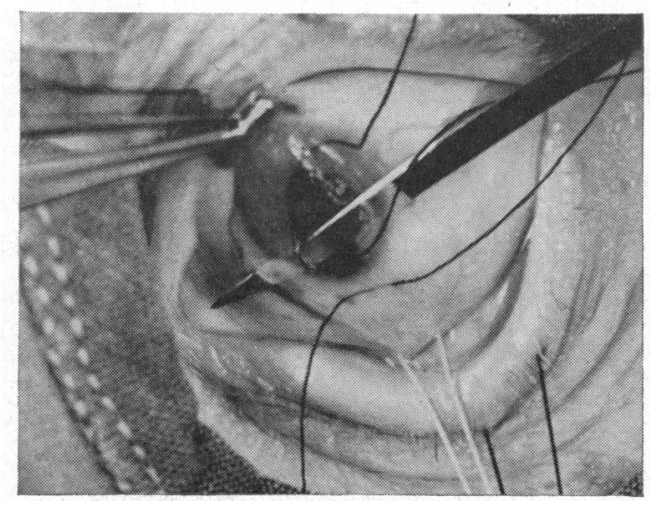

Fig. 2.-Corneo-scleral suture in place and section being made with a von Graefe knife, centred at the 6 o'clock meridian, the eye being held by Barraquer's forceps at 12 o'clock and a stay suture round the inferior rectus muscle.

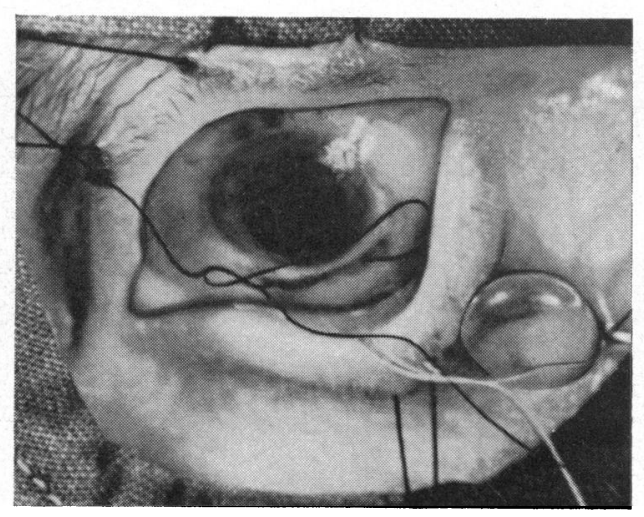

FIG. 4.-Extraction completed.

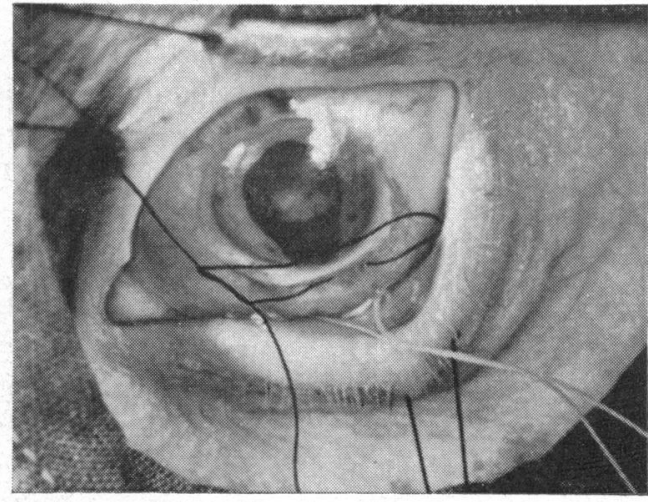

FIG. 3.-Corneo-scleral suture loosely tied and section completed.

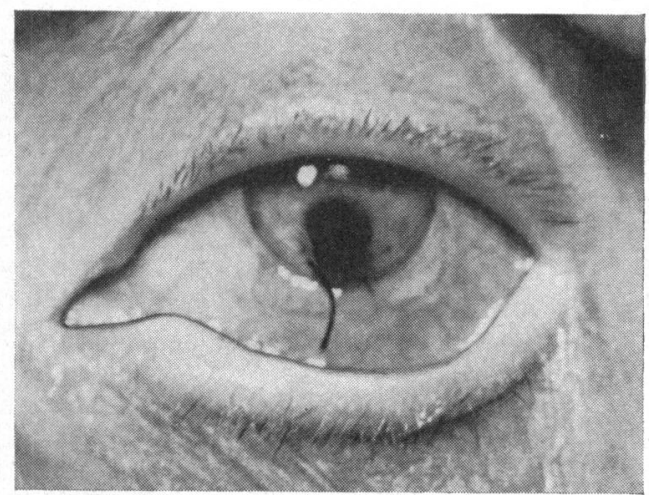

Fig. 5.-Final stage, showing corneo-scleral mattress suture firmly tied. 
Post-Operative Management.-The course of events after operation went smoothly and without incident. The patient was nursed flat in bed for the first 24 hours, after which the head was gradually raised, and the patient was asked to keep looking downwards as much as possible. The corneo-scleral suture was removed on the 14th day, and within 3 weeks the corrected vision was $6 / 60$.

Result.-The distance vision was never improved beyond this level, but in spite of extensive colobomatous involvement of the optic disc and lower retina, the corrected reading vision was N.8 (by the British Faculty of Ophthalmologists Standard Notation).

\section{Discussion}

Extraction of a cataract through a congenital coloboma of the iris has not to my knowledge been described before. In an eye with congenital defects unexpected complications are always liable to occur during operation. Accurate preoperative assessments are not always possible, and therefore adequate safeguards may not be instituted.

The success of the operation here described may be due to the steps taken to produce a low intra-ocular pressure, and in spite of the common fear of delay in consolidation of a section in the lower hemisphere, this was not encountered. The extraction of a cataract through a typical coloboma of the iris seems, therefore, to be an eminently practicable manoeuvre.

I am indebted to Dr. A. R. McKelvie for sending the case described in this article, and Mr. Thomas Meikle, Medical Photographer at Ballochmyle Hospital, and Mr. Gabriel Donald of the Department of Medical Illustration, University of Glasgow, for their help with the illustrations.

\section{REFERENCES}

BeHNKe, H. (1965). Klin. Mbl. Augenheilk., 146, 94.

Clarke, Bancroft, Allen, Wang, and Eaton (1954). "The Incidence of Visual Defects". New Orleans (Quoted by Duke-Elder (1964), p. 457).

Duke-Elder, S. (1964). "System of Ophthalmology", vol. 3, pt 2, p. $469 . \quad$ Kimpton, London. 